\title{
Human successive discrimination reversal: Effects of overtraining and reinforcement
}

\author{
THOMAS E. SITTERLEY AND JACK E. CAPEHART
}

UNIVERSITY OF ARIZONA

The overtraining reversal effect (ORE) was found in a human successive discrimination task. Two types of reinforcement were used, with three levels of training on the original problem. The ORE appeared with the first level of overtraining and then became practically asymptotic with additional overtraining.

A recent review of the effect of overtraining on habit reversals in rats (Paul, 1965), reports 13 published experiments showing a facilitative effect of overtraining on reversal, and 19 published experiments which fail to show facilitation. Paul reports that the weight of evidence suggests that the overtraining reversal effect (ORE) is more likely to be found for visual discrimination tasks than for spatial or position discrimination tasks.

There have been only a few investigations of the ORE with human Ss. One of these examined the effect of overtraining and delay on the learning of a spatial reversal in children 6 to 8 years of age (Stevenson \& Weir, 1959). They found that overtraining had no facilitory effect on reversal; however, delay did facilitate reversal (as measured by number of trials to a criterion of six correct). The authors suggest that overtraining has the greatest effect when motivation is low, and that throughout their experiment, the children enjoyed the task and were highly motivated to please the experimenter.

Youniss \& Furth (1964) report an experiment designed to replicate, in part, the study by Stevenson and Weir. Instead of spatial responses, they used one-digit numbers as the response to colored stimuli cards. The Ss were third grade students. The results showed that both overtraining and delay facilitated reversal of the original task. The authors interpret the facilitation of overtraining according to the discriminable change hypothesis (Capaldi \& Stevenson, 1957), that is, with overtraining, the reinforcement change following reversal was more clearly discriminable for the overtrained groups than when reversal followed criterial training.

Some doubt remains concerning the parameters influencing the occurrance of the ORE. It appears that the nature of the task, reinforcement, and the type of species examined are factors which may influence the presence of a facilitory effect of overtraining on reversal. A task of discriminating the oddness or evenness of digit pairs was chosen in order to increase the difficulty for the $S$, so that the task would not be learned too quickly, thus precluding the appearance of the ORE.
Two conditions of reinforcement were utilized, one with only a positive reinforcer, and the second with both positive and negative reinforcers.

Subjects

The Ss were 79 experimentally naive students enrolled at the University of Arizona. Of the total, 25 did not reach the acquisition criterion within 100 trials and were eliminated for failure to learn the original task. The remaining 54 Ss (31 females and 23 males) had a mean age of 20.2 years (range 17 to 37 years).

Apparatus

The Bisensory Unilateral Response Processor (BURP), described by Chambers \& Bartlett (1962), is an electronic logic device capable of presenting a series of stimuli in a pre-programmed sequence of order and interval. Connected to the BURP was an aluminum subject display panel, through which shone two miniature Nixie tubes (.5 in. diameter, Model 7009) horizontally separated by 1.75 in. These Nixie tubes presented randomized pairs of digits, either odd (11, $33,13,31)$ or even $(22,44,24,42)$, controlled in stepping rate by E. A 1 in. diameter green jewel reinforcement light, was flush mounted on the top of the display panel. The buzzer, a Kiho electric horn (No. 1390 ), of presumed noxious tone, was mounted behind the display panel.

The $S$, isolated from $E$, was seated in a small air conditioned, sound proof room. A one-way window allowed $E$ to continually observe $S$, and an intercommunication system allowed $\mathrm{E}$ to monitor $\mathrm{S}$ while allowing "push-to-talk" capability for $\mathrm{E}$.

Procedure

There were two reinforcement groups: Group NoBuzzer (NB) $(\mathrm{N}=36)$, which had a green light presented following a correct response only; and Group Buzzer (B) $(\mathrm{N}=18)$ which had a green light presented following a correct response and a buzzer presented following an incorrect response. Each group was divided into three treatment groups corresponding to the levels of acquisition training on the original task: Criterion (C) which required 8 out of 10 responses correct, Overtraining A (OTa) which required 13 out of 15 responses correct, and Overtraining $\mathrm{B}$ (OTb) requiring 18 out of 20 responses correct.

In the original acquisition, the verbal response "right" was positively reinforced for the even pairs, and "left" for the odd pairs, for one-half of the Ss; the other half received the opposite reinforcement contingency. In effect, the data indicated that the overtraining groups could be considered as $\mathrm{C}$ plus 5 cor- 
rect responses and $\mathrm{C}$ plus 10 correct responses. Upon completion of the original acquisition phase, the task was reversed (response "right" was reinforced for the odd pairs and "left" for the even pairs) and the number of trials to correct consistant reversal (first correct response in the series of 18 out of 20 correct responses) was recorded.

At the beginning of the experimental session, the Ss were read a standard set of instructions. The instructions informed the Ss that there was something about the pair of digits that would "tell" them to make a verbal response of "right" or "left," that it was possible to make a correct choice for every pair, and that they were to make as many correct choices as they possibly could.

Following a correct response, the green reinforcement light was turned on, and remained on until the next stimulus pair was presented. For Group B, the buzzer remained on after an incorrect response for 3 sec. The stimuli remained on until the $S$ made a response, and there were $12 \mathrm{sec}$. between stimuli during which time the $\mathrm{E}$ recorded the response on preprinted data sheets.

\section{Resulis and Discussion}

The primary data were the number of trials to reversal as a function of the type of reinforcement and the three levels of training. Figure 1 graphically shows

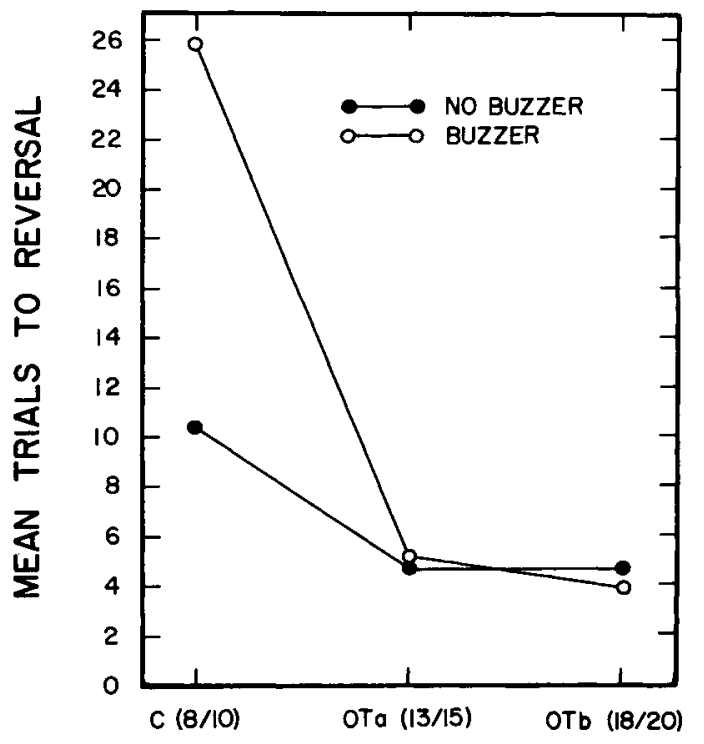

\section{LEVELS OF TRAINING}

Fig. 1. Mean number of trials to correct reversal as a function of level of training and type of reinforcement. the mean number of trials to correct reversal as a function of the level of training and the presence or absence of the buzzer. A 2 by 3 analysis of variance showed that the effect of the levels of training was significant $(p<.001)$, as was the reinforcement group effect and the level of training by group interaction $(p<.05)$.

Orthogonal comparisons were used to independently test the effect of the levels of training on each of the reinforcement groups. The criterion vs. overtrained groups comparison was significant for both Group NB and B $(p<.01)$. The OTa vs. OTb comparison was not significant for either reinforcement group.

The results showed that fewer trials were required to learn the reversal with overtraining than with criterial training. No increased facilitation occurred with increased overtraining within the overtraining limits examined. It may be concluded, that for this study, utilizing a successive discrimination with adult humans, overtraining did facilitate reversal learning up to a point. Beyond this point, further overtraining had no facilitative effects upon reversal.

While the type of reinforcement was a significant variable, this appeared mainly to be due to a decrement in reversal performance for Group $B$ at the criterion level of training. The presence or absence of the buzzer had little or no effect on the overtrained groups. How much importance should be placed upon this finding is open to question. It does point out, however, that the nature of the reinforcement does play a part in the ORE, and that its effect may not be constant for all levels of training. Likewise, it does not appear unlikely that nature of the reinforcer may be responsible for the lack of appearance of the ORE in studies which have failed to find overtraining facilitation in reversal situations.

On the basis of the post-experiment verbal reports of the Ss, the ORE appears to be due to the fact that Ss at the end of criterial training are sampling a larger cue population than Ss after higher levels of training. In effect, the overtrained Ss have eliminated a greater number of possible solutions to the problem and are better able to note the change in reward contingencies at the onset of the reversal training.

\section{References}

Chambers, R. W., \& Bartlett, N. R. A device for research in human information processing capacity. Percept. mot. Skills, 1962, 15, 343-350.

Paul, Coleman. Effects of overlearning upon single habit reversal in rats. Psychol. Bull., 1965, 63, 65-72.

Stevenson, H. W., \& Weir, M. Response shift as a function of overtraining and delay. J. comp. physiol. Psychol., 1959, 52, 327329 .

Youniss, J., \& Furth, H. G. Reversal learning in children as a function of overtraining and delayed transfer. J. comp. physiol. Psychol., 1964, 57, 155-157. 